\title{
Radioembolization for Metastatic Neuroendocrine Tumors
}

\author{
Ghassan El-Haddad, $\mathrm{MD}^{1}{ }^{10}$ Jonathan Strosberg, $\mathrm{MD}^{2}{ }^{-}$ \\ ${ }^{1}$ Radionuclide Therapy Program, Department of Diagnostic Imaging \\ and Interventional Radiology, $\mathrm{H}$. Lee Moffitt Cancer Center and \\ Research Institute, Tampa, Florida \\ 2 Department of Gastrointestinal Oncology, H. Lee Moffitt Cancer \\ Center and Research Institute, Tampa, Florida \\ Address for correspondence Ghassan El-Haddad, MD, Radionuclide \\ Therapy Program, Department of Diagnostic Imaging and \\ Interventional Radiology, H. Lee Moffitt Cancer Center and Research \\ Institute, 12902 Magnolia Dr, Tampa, FL 33612, \\ (e-mail: Ghassan.elhaddad@moffitt.org).
}

Dig Dis Interv 2021;5:103-112.

\begin{abstract}
Keywords

- radioembolization

- yttrium-90

- neuroendocrine tumor

Transarterial radioembolization (TARE) using $\beta$-emitting yttrium-90 microspheres has been used for decades in patients with liver-dominant unresectable metastatic neuroendocrine tumors (mNETs). TARE is one of the embolotherapies supported by the National Comprehensive Cancer Network, among other guidelines, for progressive or symptomatic liver-dominant mNETs. Initial studies with relatively short-term followup have indicated that TARE is likely to be at least as effective in controlling symptoms and/or disease progression in the liver as bland or chemoembolization. However, more recent data have shed new light on the risk of long-term hepatotoxicity in patients with mNETs treated with TARE. In this article, we will discuss rationale for TARE, clinical indications, outcomes, and toxicity, as well as new strategies to enhance efficacy of TARE while reducing its toxicity in the treatment of liver-dominant mNETs.
\end{abstract}

Neuroendocrine tumors (NETs) have been increasing in incidence in the last four decades, and gastroenteropancreatic NETs (GEP-NETs) are currently the second most prevalent gastrointestinal cancer after colon cancer. ${ }^{1}$ The liver is the most common site of metastasis from NETs ${ }^{2}$ : up to $75 \%$ of patients with advanced small bowel NETs, $85 \%$ of patients with pancreatic NETs, and 66\% of metastatic lung NETs develop liver metastases during the course of their disease. ${ }^{3,4}$ Neuroendocrine tumor liver metastases (NETLMs) are associated with a relatively poor prognosis ${ }^{5,6}$ secondary to considerable morbidity from hormonal symptoms such as carcinoid syndrome ${ }^{7,8}$ or tumor bulk which can ultimately lead to liver failure. ${ }^{9}$

In patients who are not surgical or ablation candidates, hepatic intra-arterial therapies (IAT) including transarterial bland embolization (TAE), transarterial chemoembolization (TACE), and transarterial radioembolization (TARE) are indicated to reduce tumor burden, slow down the growth or progression of the disease, and improve quality of life by controlling symptoms related to tumor bulk and/or secretion received

accepted after revision

March 15, 2021
March 3, 2021 of hormones. ${ }^{10,11}$ There is generally no preference for the embolotherapies among interventional radiologists. ${ }^{12}$ Despite early data suggesting that TARE has fewer short-term adverse events than other embolotherapies, concerns about chronic toxicity following TARE have emerged. ${ }^{13}$

In this article, we will explain the rationale behind using TARE for NETLMs; review the available data, including potential short- and long-term risks; and propose a new vision on how and where to use TARE in this patient population.

\section{Rationale for Transarterial Radioembolization}

Primary and secondary liver tumors receive the majority of their blood supply from the hepatic arteries rather than portal vein, ${ }^{14}$ which make the liver a suitable organ for IATs. In addition, TARE relies on the increased vascularity of liver tumors to concentrate the radioactive microspheres preferentially into the terminal arterioles of tumors relative $\begin{array}{ll}\text { (c) 2021. Thieme. All rights reserved. } & \text { DOI https://doi.org/ } \\ \text { Thieme Medical Publishers, Inc., } & \text { 10.1055/s-0041-1729755. } \\ 333 \text { Seventh Avenue, 18th Floor, } & \text { ISSN 2472-8721. }\end{array}$
Issue Theme Y-90; Guest Editors, Ripal T. Gandhi, MD, FSIR, FSVM and Suvranu Ganguli, MD, FSIR 
to normal liver parenchyma. Explanted livers treated with TARE (whether yttrium-90 $\left({ }^{90} \mathrm{Y}\right)$ resin or glass microspheres) demonstrated preferential accumulation of the radioactive microspheres mainly at the periphery and in nonnecrotic parts of tumors as opposed to normal liver parenchyma. ${ }^{15,16}$

NETLMs, especially from GEP-NETs, are usually hypervascular on arterial phase of multiphasic cross-sectional imaging, ${ }^{17}$ which theoretically make them an ideal target of intra-arterial delivery of therapy. However, a basic approach of evaluating one time point of arterial hyperenhancement did not correlate with outcome of TARE in a small study of 17 patients with NETLMs. ${ }^{18}$ This lack of correlation between tumoral enhancement at one time-point multiphasic imaging and post-TARE outcomes was also noted when studying 137 patients with multiple histologies (only 19 with NETLMs). ${ }^{19}$ These findings could be related to the small number of patients included in these retrospective studies, wide variety of tumor types, different imaging characteristics and tumor enhancement depending on the site of origin, ${ }^{17}$ and/or subjective basic imaging techniques used in determining tumor vascularity. ${ }^{19}$

Other more sophisticated techniques investigating arterial tumor enhancement fraction (the quotient of arterial phase enhancement divided by portal venous phase enhancement) predicted response to TARE in colorectal cancer. ${ }^{20}$ Similarly, quantification of arterial perfusion (AP) in a heterogeneous patient population of mainly colorectal metastases yielded a 91\% sensitivity and 95\% specificity for predicting short-term morphologic response and 1-year survival with TARE. ${ }^{21}$ In this study, AP determined by perfusion CT was the best single, independent predictor of survival with TARE as compared with multiphase CT and even ${ }^{99 \mathrm{~m}}$ Tc macroaggregated albumin $\left({ }^{99 \mathrm{~m}} \mathrm{Tc}\right.$ MAA) SPECT. This indicated that TARE is effective when administered to patients with a high AP irrespective of underlying primary malignancy or extension of hepatic metastatic disease. ${ }^{21}$ Unfortunately, this study did not include any patients with metastatic NET, and therefore, extrapolation of the findings to NETLMs is limited. The majority of GEP-NETs are hypervascular as determined by angiography and basic enhancement pattern on cross-sectional imaging ${ }^{17}$ (-Fig. 1). It is likely that well-circumscribed, uniformly hypervascular NETLMs are optimal candidates for TARE. The use of TARE in hypovascular NETLMs should be done carefully, and likely reserved for patients having rapidly progressing disease.

\section{Mechanism of Action}

TARE relies predominantly on the radiation effect, with a minor contribution from microembolization. ${ }^{22}{ }^{90} \mathrm{Y}$ is a pure $\beta$-emitting isotope with an average energy of $0.9367 \mathrm{MeV}$, a mean tissue penetration of $2.5 \mathrm{~mm}$ and a maximum tissue penetration of $11 \mathrm{~mm} \cdot{ }^{23,24}{ }^{90} \mathrm{Y}$ has a physical half-life of 64.2 hours. This allows the delivery of high radiation doses to hepatic tumors with a "cross-fire" 25 mechanism between the ${ }^{90} \mathrm{Y}$ microspheres. The absorbed dose in the tumors and liver depends on hemodynamics and intratumoral vessel density, ${ }^{26}$ with preferential implantation of the microspheres at

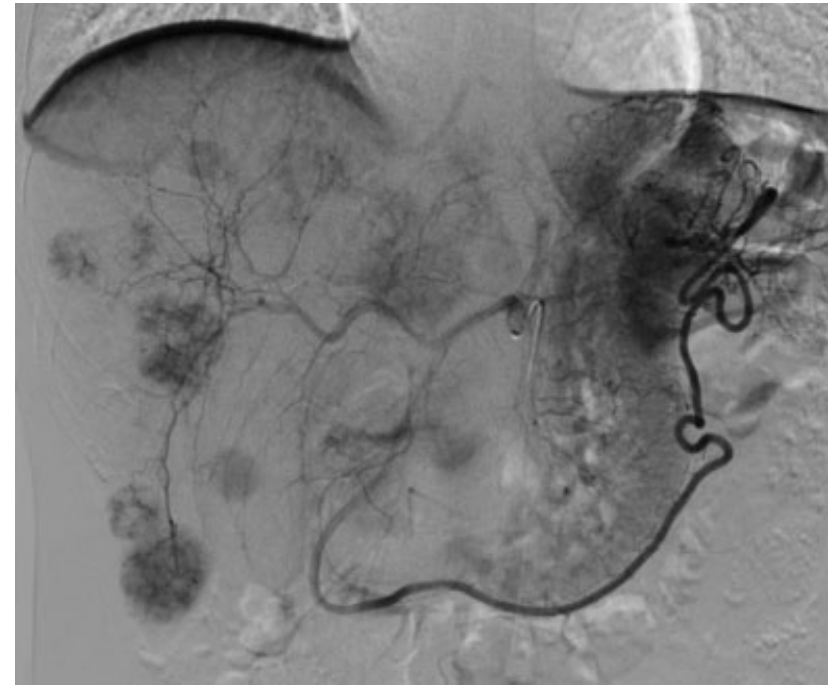

Fig. 1 Multifocal bilobar hypervascular liver lesions in a 50-year-old woman with metastatic pancreatic neuroendocrine tumor. Most neuroendocrine tumor liver metastases are hypervascular making them suitable for intra-arterial therapies.

the periphery of tumors ${ }^{16}$ in the terminal arterioles. ${ }^{25}$ The deposition of microspheres in the tumors in comparison to normal liver is variable with tumor to normal (T:N) ratio ranging between $3: 1$ and 20:1, but in general liver metastases have a T:N between 4 and $5 .^{21,27}$ The antitumoral effect of ${ }^{90} \mathrm{Y}$ relies on adequate oxygenation of targeted tissue ${ }^{28}$ and is thought to be secondary to irreversible damage to tumor epithelial, stromal, and endothelial cells. ${ }^{29}$ The characteristics of the two approved TARE devices in the United States, the ${ }^{90} Y$ glass microspheres (TheraSphere; Boston Scientific, Marlborough, MA) and ${ }^{90} \mathrm{Y}$ resin microspheres (SIR-Spheres; Sirtex Medical, Sydney, Australia), are presented in - Table 1.

\section{Patient Selection}

The goal of TARE, like other IATs, is to "reset the clock" in NETLMs, control progression of liver disease and local mass effect, reduce hormonal symptoms, reduce risk of carcinoid heart disease, and delay liver failure. The indications for use of TARE in NETLMs include:

- Liver-dominant disease.

- Progressive liver disease.

- Uncontrolled hormonal production despite use of somatostatin analog (SSA).

- Symptoms from bulky disease (i.e., abdominal pain, compression of vital structures such as bile ducts, portal vein; -Fig. 2).

\section{Exclusion Criteria}

In general, patients are not considered good candidates for TARE if they have:

- Eastern Cooperative Oncology Group (ECOG) performance status $>2$.

- Elevated baseline bilirubin ( $>2 \mathrm{mg} / \mathrm{dL}$ ), unless highly selective treatment can be performed. 
Table 1 Characteristics of commercially available ${ }^{90} \mathrm{Y}$ microspheres in the United States

\begin{tabular}{|l|l|l|}
\hline & ${ }^{90}$ Y glass microspheres & ${ }^{90}$ Y resin microspheres \\
\hline Microsphere mean diameter & $25 \pm 10 \mu \mathrm{m}$ & $35 \pm 10 \mu \mathrm{m}$ \\
\hline Matrix & Insoluble, biocompatible resin & Insoluble, biocompatible glass \\
\hline Density & $3.6 \mathrm{~g} / \mathrm{dL}$ & $1.6 \mathrm{~g} / \mathrm{dL}$ \\
\hline $\begin{array}{l}\text { Mean radioactivity per micro- } \\
\text { sphere at the time of calibration }\end{array}$ & $2,500 \mathrm{~Bq}$ & $50 \mathrm{~Bq}$ \\
\hline $\begin{array}{l}\text { Methods used to calculate activity } \\
\text { to be injected }\end{array}$ & MIRD & BSA, partition model \\
\hline $\begin{array}{l}\text { Vials available with different } \\
\text { activities }\end{array}$ & $\begin{array}{l}\text { Standard: 3, 5, 7, 10, 15, 20 GBq } \\
\text { Custom vials 3-20 GBq can be ordered at } \\
0.5-G B q \text { increments }\end{array}$ & $\begin{array}{l}3.0 \mathrm{GBq} \text { : day of calibration } \\
5.3 \mathrm{GBq} \text { : } 1 \text { day precalibration } \\
7.3 \text { GBq: } 3 \text { days precalibration }\end{array}$ \\
\hline Spheres per vial & $\begin{array}{l}\text { About 400,000 per GBq (i.e., 1.2 million } \\
\text { for 3 GBq, } 8 \text { million for 20 GBq) }\end{array}$ & $\begin{array}{l}\text { About } 44 \pm 2.6 \text { million spheres in each } \\
\text { delivery vial }\end{array}$ \\
\hline Embolic effect & Minimal & Mild \\
\hline
\end{tabular}

Abbreviations: Bq, Becquerel; BSA, body surface area; GBq, gigabecquerel, MIRD, medical internal radiation dose.

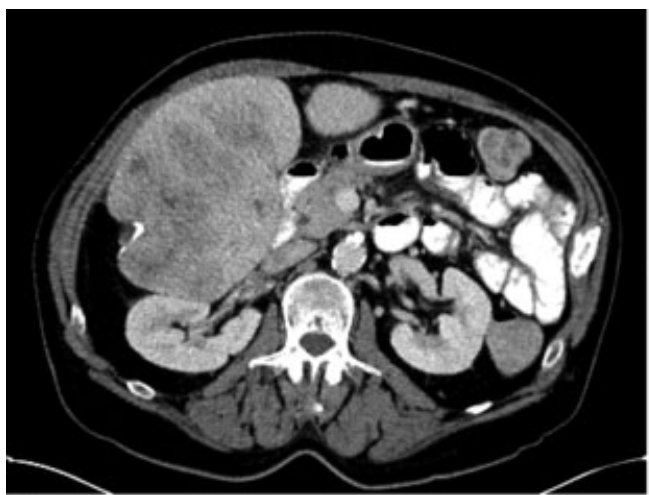

a.

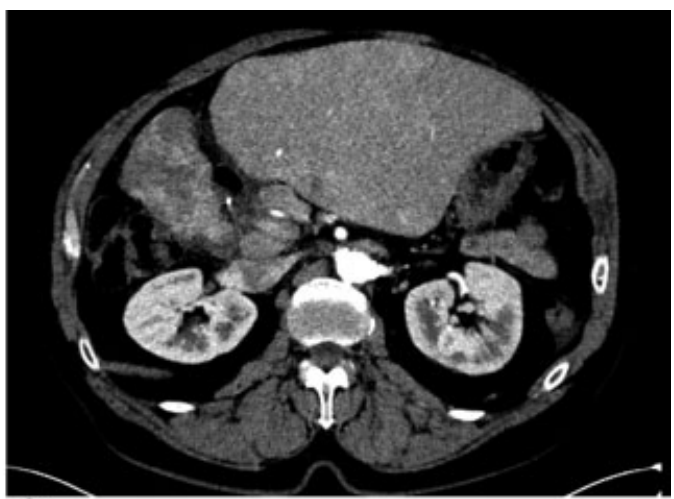

b.

Fig. 2 A 57-year-old patient with metastatic pancreatic neuroendocrine tumor causing significant abdominal pain and partial gastric outlet obstruction treated with transarterial radioembolization (TARE). Pre-TARE contrast-enhanced CT scan demonstrates a large inferior right hepatic lobe neuroendocrine tumor metastasis causing significant mass effect with abdominal bulge, compression of the duodenum, and right kidney (a). The patient's right hepatic lobe received two administrations of 1 day precalibration ${ }^{90} \mathrm{Y}$ resin microspheres 1 month apart with a total activity of $4.43 \mathrm{GBq}$. The patient's partial gastric outlet obstruction and abdominal pain started improving 1 month posttreatment and completely resolved 3 months later. A 2-year post-TARE contrast-enhanced CT scan demonstrates significant shrinkage of the right hepatic lobe and tumor with resolution of mass effect (b).

- Alanine aminotransferase or aspartate aminotransferase $>5 \times$ upper limit of normal.

- Tumor burden $>70 \%$ of the target liver volume, or tumor nodules too numerous to count.

- Tumor volume $>50 \%$ combined with an albumin $<3 \mathrm{~g} / \mathrm{dL}$.

After a patient is determined to be a candidate for TARE, a workup hepatic angiography followed by intrahepatic administration of ${ }^{99 \mathrm{~m}} \mathrm{Tc}-\mathrm{MAA}(100-150 \mathrm{MBq})$ is performed to determine tumor deposition, vascular anatomic variants, the presence of extrahepatic vascular collaterals, and the lung shunt fraction (LSF). ${ }^{24,30,31} 99 \mathrm{~m}$ Tc-MAA particles are used as a surrogate to ${ }^{90} \mathrm{Y}$ microspheres since the mean diameter is $35 \mu \mathrm{m}$. The absolute contraindications for the use of ${ }^{90} \mathrm{Y}$ microspheres following the workup angiography and ${ }^{99 m}$ Tc-MAA scintigraphy include:
- Significant hepatopulmonary shunting with an expected radiation dose to the lungs $>30 \mathrm{~Gy}$ in a single treatment or $50 \mathrm{~Gy}$ in multiple treatments.

- Extrahepatic collaterals supplying the gastrointestinal tract that cannot be avoided or coiled.

In addition, there are several relative contraindications that should be taken into consideration on individual basis including:

- Compromised pulmonary function.

- Inadequate liver reserve with ascites or encephalopathy.

- Serum creatinine $>2.0 \mathrm{mg} / \mathrm{dL}$.

- Platelet count $<50 \times 10^{9} / \mathrm{L}$.

- Severe iodinated contrast allergy.

- Life expectancy less than 3 months. 
Table 2 Different methods to calculate the ${ }^{90} \mathrm{Y}$ microsphere activity to be administered in the liver

\begin{tabular}{|c|c|c|c|}
\hline & MIRD & BSA & Partition \\
\hline $\begin{array}{l}\text { Main factors } \\
\text { affecting } \\
\text { prescribed } \\
\text { activity }\end{array}$ & $\begin{array}{l}\text { a. Perfused liver } \\
\text { mass to be treated } \\
\text { b. LSF }\end{array}$ & $\begin{array}{l}\text { a. BSA } \\
\text { b. \% of tumor } \\
\text { involvement }\end{array}$ & $\begin{array}{l}\text { a. T:N ratio } \\
\text { b. Target dose to tumor } \\
\text { c. Mass of tumor(s) } \\
\text { d. Mass of normal liver } \\
\text { e. LSF }\end{array}$ \\
\hline $\begin{array}{l}\text { Compartment } \\
\text { method }\end{array}$ & Unicompartment & & Multicompartment \\
\hline $\begin{array}{l}\text { A calculation } \\
(\mathrm{GBq})\end{array}$ & $=\frac{[\text { target dose }(\text { Gy }) \times \text { target liver mass }(\mathrm{kg})]}{50 \times(1-\text { LSF })}$ & $=[\mathrm{BSA}(\mathrm{m} 2)-0.2]+\frac{V t}{V t+V n}$ & $=D n(G y) \frac{\frac{T}{N} \times M t(k g)+M n(k g)}{50\left(\frac{J}{G B q}\right) \times(1-\text { LSF })}$ \\
\hline
\end{tabular}

Abbreviations: A, activity; BSA, body surface area; Dn, dose to normal tissue; LSF, lung shunt fraction; MIRD, medical internal radiation dose; Mn, mass of normal liver; Mt, mass of tumor(s); T:N, tumor to normal ratio; Vn, volume of normal liver tissue; Vt, volume of tumor(s).

- Tumor burden less than $20 \%$ for bilobar treatment.

While most of these inclusion and exclusion criteria are similar to TAE/TACE, a major difference is that portal vein thrombosis (PVT) is not a contraindication to TARE because the embolic effect is minimal compared with TAE/TACE. In patients with bilobar disease, the liver is treated one lobe at a time in 4 to 6 weeks apart as long the patient has recovered from initial embolization.

\section{Dosimetry}

Radioembolization treatment planning for ${ }^{90} \mathrm{Y}$ glass microspheres (TheraSphere; Boston Scientific) and ${ }^{90} \mathrm{Y}$ resin microspheres (SIR-spheres; Sirtex Medical) is quite different, but in both cases relies on semi-empirical methods. Currently, the radiation activity determination for ${ }^{90} \mathrm{Y}$ resin microspheres is based mostly on body surface area (BSA), and to a lesser extent on the multicompartmental partition model (PM). The BSA model is most commonly used due to its simplicity, as it assumes a theoretical liver volume, and the modified BSA model takes into account the percentage of tumor involvement. ${ }^{32}$ The BSA model has been used in multiple randomized clinical trials with acceptable toxicity profile. ${ }^{33}$ However, this method is criticized as it can lead to patients being either over- or underdosed. The PM is more personalized, as it incorporates the T:N uptake ratio, but is used less widely as it is a bit more complex. The PM is criticized for assuming uniform distribution of microspheres in the normal liver and tumors; for practical reasons, the T:N ratio is usually estimated rather than calculated. Radiation activity determination for ${ }^{90}$ Y glass microspheres is based on the medical internal radiation dose (MIRD) model, which is a unicompartmental model assuming uniform distribution of microspheres in the perfused volume. ${ }^{32}$ This can result in a wide variation of dose delivered to the tumors and normal liver parenchyma depending on the tumor burden and vascularity of the lesions. Similar to BSA, the MIRD model has been used for ${ }^{90} \mathrm{Y}$ glass microspheres with acceptable toxicities. ${ }^{34,35}$ The different ${ }^{90} \mathrm{Y}$ microspheres activity calculation models are presented in - Table 2.

There is a growing interest in voxel-based dose calculation treatment planning software. ${ }^{36,37}$ A voxel-based dosimetry relies on the counts emitted from a three-dimensional pixel on a post-TARE positron emission tomography (PET; or single photon emission tomography [SPECT]) scan. Multiple companies have received clearance by the U.S. Food and Drug Administration (FDA) for this purpose. Ideally, a pre-TARE estimation of microsphere distribution would be able to better predict the dose distribution. However, ${ }^{99 \mathrm{~m}} \mathrm{Tc}$-MAA, the only currently available surrogate to ${ }^{90} \mathrm{Y}$ microspheres, has many limitations, including a percentage of particles outside the 10 - to $90-\mu \mathrm{m}$ range, particle breakdown, and overestimation of $\mathrm{LSF}^{38-40}$ Most importantly, ${ }^{99 \mathrm{~m}} \mathrm{Tc}-\mathrm{MAA}$ distribution may not exactly model ${ }^{90} \mathrm{Y}$ microsphere distribution. Many studies showed weak correlation between ${ }^{99 \mathrm{~m}} \mathrm{Tc}-\mathrm{MAA}$ SPECT and distribution of ${ }^{90} \mathrm{Y}$ resin microspheres in metastatic colorectal cancer (mCRC), ${ }^{38,41,42}$ while others showed better correlation in predicting response and survival in patients with HCC when using ${ }^{90} \mathrm{Y}$ glass microspheres. $^{43-45}$ This inconsistency in correlation is possibly related to the difference in the number of microspheres, the embolic effect of resin microspheres, and differences in tumor perfusion. NETLMs have an enhancement pattern closer to HCC than mCRC. However, it is unclear whether there is a strong correlation between the distribution of ${ }^{99 \mathrm{~m}} \mathrm{Tc}-\mathrm{MAA}$ and ${ }^{90} \mathrm{Y}$ glass or resin microspheres when treating NETLMs. While data related to dose distribution in the treatment of NETLMs are still lacking, a small study of 15 patients with NETLMs treated with ${ }^{90} \mathrm{Y}$ resin microspheres found that an estimated tumor-absorbed dose $\geq 191.3 \mathrm{~Gy}$ predicted response by modified Response Evaluation Criteria in Solid Tumors (mRECIST) with 93\% specificity and $83 \%$ specificity. ${ }^{46}$ In this study, the absorbed dose was estimated using PM following manual volumes of interest on ${ }^{99 m} \mathrm{Tc}$ MAA SPECT/CT to determine T:N ratio. Twenty-five of 26 tumors (96.2\%) responded when absorbed dose was $\geq 191.3 \mathrm{~Gy}$ compared with only 5 of 19 (26.3\%) responders 
Table 3 Most common imaging guidelines used to assess response following TARE

\begin{tabular}{|c|c|c|}
\hline Guidelines & Definition & Classification \\
\hline $\mathrm{WHO}^{84}$ & $\begin{array}{l}\text { Largest area: } \\
\text { bidimensional tumor } \\
\text { measurement }\end{array}$ & $\begin{array}{l}\text { CR: } 100 \% \text { decrease in area of target lesion(s) } \\
\text { PR: } \geq 50 \% \text { decrease in area of target lesion(s) } \\
\text { SD: }<50 \% \text { decrease to } \leq 25 \% \text { increase in area of target lesion(s) } \\
\text { PD: }>25 \% \text { increase in area from maximum response of target lesion(s) } \\
\text { and/or new lesion(s) }\end{array}$ \\
\hline RECIST $^{85}$ & $\begin{array}{l}\text { Longest diameter: } \\
\text { unidimensional tumor } \\
\text { measurement }\end{array}$ & $\begin{array}{l}\text { CR: } 100 \% \text { decrease in longest diameter of target lesion(s) } \\
\text { PR: } \geq 30 \% \text { decrease in longest diameter of target lesion(s) } \\
\text { SD: }<30 \% \text { decrease to } \leq 20 \% \text { increase in longest diameter of target lesion(s) } \\
\text { PD: }>20 \% \text { increase in maximum diameter from maximum response of } \\
\text { target lesion(s) and/or new lesion(s) }\end{array}$ \\
\hline $\mathrm{mRECIST}^{86}$ & $\begin{array}{l}\text { Longest diameter of } \\
\text { enhancing tissue: } \\
\text { unidimensional } \\
\text { measurement }\end{array}$ & $\begin{array}{l}\text { CR: } 100 \% \text { decrease in enhancing tissue of target lesion(s) } \\
\text { PR: } \geq 30 \% \text { decrease in enhancing tissue of target lesion(s) } \\
\text { SD: }<30 \% \text { decrease to } \leq 20 \% \text { increase in enhancing tissue of target lesion(s) } \\
\text { PD: }>20 \% \text { increase in enhancing tissue from maximum response of target } \\
\text { lesion(s) and/or new enhancing lesion(s) }\end{array}$ \\
\hline
\end{tabular}

Abbreviations: CR, complete response; mRECIST, modified Response Evaluation Criteria in Solid Tumors; PD, progression of disease; PR, partial response; RECIST, Response Evaluation Criteria in Solid Tumors; SD, stable disease; TARE, transarterial radioembolization; WHO, World Health Organization.

when dose was less than 191.3 Gy. An absorbed tumor dose less than $72.8 \mathrm{~Gy}$ predicted no response. ${ }^{46}$

\section{Imaging Assessment of Tumor Response}

Multiphasic CT and MRI are the most commonly used standard imaging modalities to evaluate NETLMs response following TARE. Imaging interpretation guidelines include World Health Organization (WHO), RECIST, and mRECIST. ${ }^{47-49}$ By focusing on the enhancing viable tumor based on arterial enhancement using contrast-enhanced studies, mRECIST addresses the shortcomings of WHO and RECIST which are more suited to evaluate systemic therapies rather than locoregional therapies such as TARE. The most common imaging guidelines to assess response to TARE are summarized in - Table 3.

\section{Data on Transarterial Radioembolization}

Only a single pilot study of 11 patients with small bowel NETLMs randomized patients to TAE versus TARE, but the small sample size was inadequate to compare the two treatments. ${ }^{50}$ Otherwise, no randomized trials have studied the effect of TARE in NETLMs, and the degree of evidence for TARE is considered by the National Comprehensive Cancer Network (NCCN) as category 2B (based on lower-level evidence, there is consensus that the intervention is appropriate). ${ }^{13}$ Most cohort studies included data on NETLMs within a mixed population of non-NET tumor types, and the ones that focused on NETLMs comprised mostly a small number of patients, heterogeneous tumor types, with lack of details on primary tumor site and/or grading. ${ }^{49,51}$ Most data from cohort studies on TARE and NETLMs come from ${ }^{90} \mathrm{Y}$ resin rather than glass microspheres, ${ }^{48,49,51-56}$ with no standardized follow-up, and inconsistency in reporting both objective response rates (ORRs) and survival. ${ }^{49}$ Therefore, the systematic review and meta-analyses that resulted from these publications were also limited, as they included multi-institutional studies which resulted in inclusion of overlapping patients. ${ }^{49,51-53}$

\section{Radiographic Response}

Determination of radiographic response varies between studies depending on imaging criteria used and the time of imaging. Kennedy et $\mathrm{al}^{57}$ reviewed 148 patients from 10 different institutions and reported 3-month radiologic response, finding an ORR of $63.2 \%$ (60.5\% PR; $22.7 \%$ SD; $4.9 \% \mathrm{PD}$ ) and a disease control rate (DCR) of $65.1 \%$ (60.5\% PR; $4.9 \% \mathrm{PD}$ ). However, imaging criteria used to assess response was based on either RECIST or WHO when possible, or best radiographic estimate. ${ }^{57}$ In addition, stratification by prognostic factors such as tumor grade or primary tumor site was lacking in this study. A systematic review of 870 patients by Jia and Wang ${ }^{53}$ reported that median DCR at 3 months was $86 \%$ (range: $62.5-100 \%$ ) when using RECIST or WHO criteria. With a median follow-up of 25 months (range: 11.9-60 months) after TARE, the reported median values for complete response, partial response, stable disease, and progressive disease were $2.7 \%$ (range: $0-15 \%$ ), 35.3\% (range: $12.5-66.5 \%$ ), $40 \%$ (range: $14.7-75 \%$ ), and $14 \%$ (range: 0-37.5\%), respectively. ${ }^{53}$ A more recent study using RECIST 1.1 by Tsang et al ${ }^{55}$ reported $0 \%$ CR, 53\% PR, 33\% SD, $12 \% \mathrm{PD}$, and $2 \%$ unknown, which are comparable to previous results. ${ }^{58}$

A recent large retrospective multicenter study by Braat et $\mathrm{al}^{48}$ reviewed 244 patients and reported 3 - and 6-month ORR of 15.7 and $28.5 \%$, respectively, with a DCR of 91.3 and 91.4\%, respectively, when using RECIST v1.1. When modified RECIST (mRECIST) was used, the 6-month ORR was $62.9 \%$ with DCR of $91.4 \%{ }^{48}$ This is in line with publication by Zuckerman et $\mathrm{al}^{56}$ which also used mRECIST and found $5.1 \% \mathrm{CR}, 45.8 \% \mathrm{PR}, 30.5 \% \mathrm{SD}$, and $6.8 \% \mathrm{PD}$ response rates. 


\section{Symptom Control}

With regard to symptom control, Braat et $\mathrm{al}^{48}$ reported an overall response in $79 \%$ of patients; $44 \%$ had complete response and $35 \%$ had partial response. ${ }^{48}$ In the systematic review by Jia and Wang, ${ }^{53} 69 \%$ of patients had improvement in their carcinoid syndrome. These results are comparable to TAE (64-93\%), and TACE (60-95\%) in terms of symptomatic improvement. ${ }^{59}$ Engelman et al found no difference in the rate of symptom control between TAE, TACE, and TARE. ${ }^{60}$

\section{Survival}

A meta-analysis and systematic review by Frilling et $\mathrm{al}^{52}$ and Jia and Wang, ${ }^{53}$ evaluating 19 and 11 retrospective studies, found a median general OS of 28 months (range: 14-70 months) and 32 months (range: 18-57 months) after TARE, respectively. When stratified by tumor types, the median OS for patients with small bowel, pancreatic, and unclassified NETs were 56, 31, and 28 months, respectively, and when stratified by tumor grade, median OS for grade I, II, and III NETs were 71, 56, and 28 months, respectively. ${ }^{53}$ These results should be interpreted with caution since up to $19.8 \%$ (77 out of 388 ) of patients in the 11 studies reviewed by Jia and Wang ${ }^{53}$ underwent TAE or TACE before TARE.

In 2017, Chen et $\mathrm{al}^{54}$ presented the results of a multicenter retrospective study of 155 patients with NETLMs from different sites, mostly pancreas $(n=71)$ and gastrointestinal $(n=68)$, who were treated with TACE $(n=50)$, TARE $(n=64)$, or TAE $(n=41)$. In this large retrospective study with propensity score analysis, there was no significant difference between embolotherapies, and no difference between ${ }^{90} \mathrm{Y}$ resin $(n=43)$ and glass $(n=21)$ with a hepatic progressionfree survival (HPFS) of 14.9 and 23.4 months, respectively. With regard to post-TARE OS, the results were similar to prior TARE-only series, ${ }^{47,57,61,62}$ with no difference between resin (48.2 months) and glass TARE (51.6 months). However, interestingly there was a trend toward worsened prognosis with TARE versus TACE, ${ }^{54}$ which was seen in a previous study comparing these two treatment modalities. ${ }^{63}$

Tsang el $\mathrm{al}^{55}$ reported on 49 patients treated mostly with ${ }^{90} \mathrm{Y}$ resin TARE (SIR-Spheres 69\%, TheraSphere 29\%, 2\% unknown; between June 2011 and January 2017 across six regional centers in British Columbia, Canada). The median OS of this group was 27.2 months (95\% CI: 8.0-46.5), which is comparable to previously reported outcomes that measured from 22 to 70 months. ${ }^{58}$

More recently, Braat el $\mathrm{al}^{48}$ reported the results on ${ }^{90} \mathrm{Y}$ resin microspheres from eight different institutions in the United States and Europe that found a median OS after TARE for NETLMs of 31.2 months (range: 1.7-144 months; $95 \% \mathrm{CI}$ : 26.4-36 months). This study provided more data on NETLMs from different primary sites and grades, and found, as expected, a shorter OS for higher grades $(p<0.001)$ : median OS was 37.2 months (95\% CI: 31.2-44.4), 28.8 months (95\% CI: 22.8-36), and 10.8 months (95\% CI: $1.2-22.8)$ in G1, G2, and G3 NET/neuroendocrine carcinoma (NEC), respectively.
Zuckerman et $\mathrm{al}^{56}$ reported on 59 patients from a single academic center who were treated between 2009 and 2015 mostly with TARE (SIR-Spheres 64\%, TheraSphere 46\%; mean administered activity 1.71 and $5.43 \mathrm{GBq}$, respectively). Median HPFS was 18 months (95\% CI: 13-27) and the median OS was 31 months (95\% CI: 27 months to unreached).

Factors that are commonly found to be predictive of better OS after TARE are female gender, well-differentiated tumor, low $\mathrm{K}_{\mathrm{i}}-67$, good performance status, low hepatic tumor burden, and absence of extrahepatic metastases. ${ }^{48,53-55}$

A recent two-institution retrospective analysis showed no difference on long-term PFS or OS between TACE and TARE, despite TACE showing a greater DCR. ${ }^{64}$

\section{Toxicity}

Short-term toxicities following TARE have been described as minor, and in 2015 a multidisciplinary group of experts convened to form the NET-Liver-Metastases Conference that reviewed 11 reports on TAE or TACE and 7 on TARE. ${ }^{49}$ In this meeting, TARE was considered to have advantages over TAE and TACE because of fewer side effects. However, the guidelines were based on data from small retrospective studies and included papers that either did not report on toxicity $^{65}$ or reported toxicity up to 6 months. ${ }^{61,66}$ Most short-term side effects post-TARE, including abdominal pain (median: $32.6 \%$, range: $2.7-100 \%$ ), nausea/vomiting (median: $32.5 \%$, range: $3.2-100 \%$ ), and fatigue (median: $30.4 \%$, range: $6.5-63 \%),{ }^{53}$ are mild and transient. Additionally, the most frequent hematological complications of TARE are lymphocytopenia (6.7\%) and thrombocytopenia (3\%). ${ }^{48}$ More serious complications are less common $(<1 \%)$ and usually related to nonrecognition of extrahepatic vascular collaterals and nontargeted embolization resulting in cholecystitis, gastrointestinal ulcers, and gastritis. ${ }^{53,67,68}$ In Jia and Wang's systematic review, only one early death due to hepatic failure post-TARE was reported in more than 800 patients. ${ }^{53}$ Patients who had previous biliary instrumentation have a higher risk for cholangitis and liver abscess after embolization due to bacterial colonization of the biliary tree. The risk of infectious complications is lower after TARE ( $\sim 10 \%)$ than after TAE/TACE ( $\sim 20 \%)$ despite broad-spectrum antibiotic coverage. ${ }^{13,69}{ }^{90} \mathrm{Y}$ glass microspheres appear to carry a higher risk than resin microspheres, which might be due to higher activity per glass sphere, and smaller size leading to deeper penetration. ${ }^{69}$

In the past 4 years, several reports have emerged about the risk for long-term hepatotoxicity after TARE. ${ }^{70-72}$ This phenomenon was labeled as radioembolization-induced chronic hepatotoxicity, ${ }^{71}$ occurring at least 6 months after TARE and manifesting as cirrhosis-like morphology, liver dysfunction, and ascites. ${ }^{49,70,71,73}$ In a retrospective study of 39 patients with NETLMs treated with ${ }^{90} \mathrm{Y}$ glass and a follow-up of more than 2 years, Su et $\mathrm{al}^{70}$ found that the median time to cirrhosis-like morphology was 1.8 years. This developed in $56.4 \%$ (22/39) of patients who received bilobar TARE, and even though there was no overall significant change in liver volume, the spleen did increase significantly 
in size and the platelet and albumin decreased significantly over time. $41 \%(16 / 39)$ of patients developed ascites and $15.4 \%$ developed varices. These findings were supported by a retrospective review of 52 patients treated with ${ }^{90} \mathrm{Y}$ resin with more than 1 year of follow-up by Tomozawa et al ${ }^{72}$ who found that new imaging changes of cirrhosis-like morphology or portal hypertension developed in 29\% (15/52) of patients, most of who received bilobar treatment. In fact, the 29 patients who received bilobar TARE were more likely to develop cirrhosis-like morphology (6 patients [20.7\%]), ascites (5 patients [17.2\%]), splenomegaly (6 patients [20.7\%]), and varices (2 [6.9\%]), although this did not reach statistical significance. These reports lead to recent caution in NCCN guidelines with regard to routine use of TARE for bilobar NETLMs. ${ }^{13}$

In a comparative single-center retrospective study examining chronic hepatotoxicity after conventional TACE $(n=63)$ or ${ }^{90} \mathrm{Y}$ resin TARE $(n=28)$ for NETLMs at a minimum follow-up of 6 months, excluding patients with treatment crossovers and those who survived less than 1 year, there was higher chronic hepatotoxicity with TARE (bilobar in $71 \%$ of TARE cases), but without reaching statistical significance. $^{74}$

There is scarcity of data linking the amount of absorbed radiation and hepatotoxicity in NETLMs. Zuckerman et al reported three potentially treatment-related deaths secondary to hepatic failure out of 51 patients with NETLMs treated with ${ }^{90} \mathrm{Y}$ resin. ${ }^{56}$ Ten patients within the cohort underwent a posttreatment PET-MRI dosimetric analysis, and authors found that the patients who did not develop hepatotoxicity or hepatic fibrosis received a mean dose to normal liver of $25.4 \mathrm{~Gy}$, while the mean liver dose in patients who experienced toxicity (hepatic fibrosis $n=2$ and death from hepatic failure $n=1$ ) was $59.1 \mathrm{~Gy}$. Additional data are needed to determine the safe range of absorbed dose in normal liver to avoid liver toxicity while optimizing tumor response.

\section{Combination with Chemotherapy}

There are early phase 1 and 1b data on combining SIRT with everolimus and pasireotide, ${ }^{75}$ and capecitabine-temozolomide. ${ }^{76}$ These combination therapies hold promise and have so far proven safety. King et $\mathrm{al}^{77}$ prospectively studied a combination of TARE and 7-day systemic infusion of 5- fluorouracil as a radiosensitizer in 34 patients with progressive NETLMs. Symptom control was noted in 55 and $50 \%$ of patients at 3 and 6 months, respectively. Using RECIST, the overall response rate (ORR) was seen in $50 \%$ of cases, with 18 and $32 \%$ showing a complete or partial response, respectively. ${ }^{77}$ There was low toxicity in this combination, but the ORR is pretty similar to historical results of embolotherapies.

\section{Sequencing with Peptide Receptor Radionuclide Therapy}

In early 2018, the U.S. FDA approved ${ }^{177}$ Lutetium ( $\left.{ }^{177} \mathrm{Lu}\right)-$ DOTATATE for the treatment of somatostatin receptor-positive GEP-NETs. ${ }^{78}$ This was based on the results of NETTER-1 trial comparing ${ }^{177}$ Lu-DOTATATE with long-acting SSA to high-dose SSA alone in patients with progressive, welldifferentiated locally advanced/inoperable or metastatic somatostatin receptor-positive midgut NETs. ${ }^{79}$ It was also supported by data from Erasmus Medical Center, where a single-institution, single-arm, open-label trial evaluated ${ }^{177}$ Lu-DOTATATE in patients with bronchial and GEP-NET somatostatin receptor-positive tumors. ${ }^{80}$

Sequencing of liver embolotherapy and peptide receptor radionuclide therapy (PRRT) has not been well established, and is based currently on institutional preference.

In view of the emerging data on long-term hepatotoxicity following TARE, ${ }^{70,72}$ there is a concern about the potential additive effect of absorbed radiation by the liver in patients also receiving PRRT. A small retrospective analysis by Hamiditabar et $\mathrm{al}^{81}$ looking at the safety of ${ }^{177}$ Lu-DOTATATE PRRT following liver embolization in 51 patients (30 had prior TACE and/or TAE, 10 had prior TARE, and 11 had both) did not demonstrate a statistically significant increase in hepatotoxicity, but only 10 patients had prior TARE. In an earlier small case series, 10 of 17 heavily pretreated U.S. patients with embolotherapy followed by PRRT developed hepatotoxicity, ${ }^{82}$ which raised the alarm on the risks of prior radiation exposure with ${ }^{90} \mathrm{Y}$.

The efficacy and safety of ${ }^{90} \mathrm{Y}$ TARE after PRRT was addressed in a multicenter retrospective study by Braat et al. ${ }^{83}$ Forty-four patients underwent 58 TARE procedures, of which $55 \%$ were to the whole liver, at a median of 353 days after prior PRRT. By RECIST 1.1 at 3 months, the ORR was $16 \%$ and DCR was $91 \%$. Three patients developed
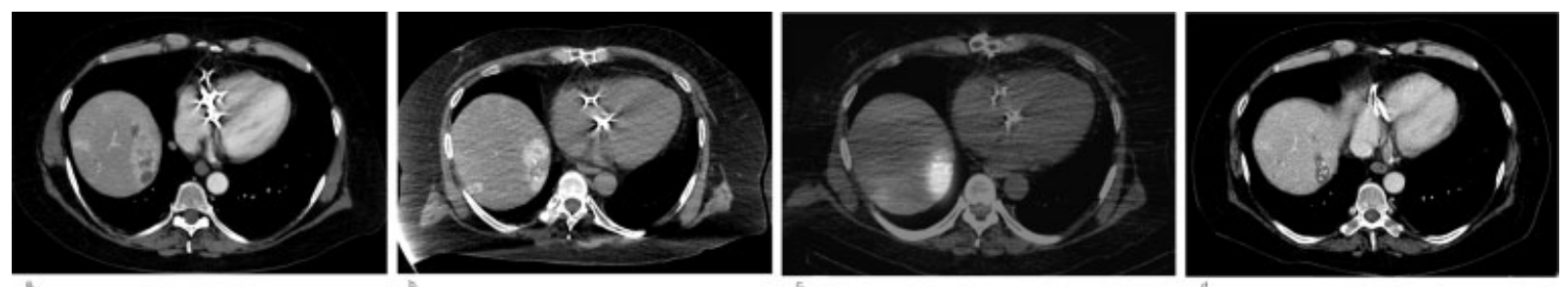

Fig. 3 A 58-year-old man with metastatic small bowel neuroendocrine tumor was referred for radiation segmentectomy of an enlarging mass in segment 7 of the liver. Pre-transarterial radioembolization contrast-enhanced CT scan demonstrates an arterially enhancing heterogeneous mass with areas of necrosis in segment 7 (a). A CT arteriogram performed during workup confirmed superselective perfusion of this lesion by segment 7 right hepatic artery branch (b). ${ }^{99 m}$ Tc MAA SPECT/CT shows intense localized activity in the tumor, significantly higher than the surrounding normal liver (c). After delivering $153 \mathrm{~Gy}$ of ${ }^{90} \mathrm{Y}$ glass microspheres in segment 7 branch, a 7-month follow-up CT scan demonstrates complete response of the tumor by modified Response Evaluation Criteria in Solid Tumors (mRECIST; d). 
radioembolization-induced liver disease and one died 20 weeks after TARE.

\section{General Recommendations for Use of TARE}

Caution should be used in patients with low-grade, bilobar NETLMs who have a long life expectancy in view of the risk of long-term hepatotoxicity. Patients with relatively aggressive tumors, or those who have previously received TAE or TACE, may be appropriate candidates for TARE. Sequential bilobar or whole liver TARE should be avoided in many circumstances, unless exposure of normal liver parenchyma is predicted to be low. Superselective radiation segmentectomy with TARE is a good option in localized unresectable or unablatable tumors (-Fig. 3). Older patients are better served with TARE due to lower acute side effects compared with TAE/TACE. Patients with prior biliary instrumentation (Whipple surgery, sphincterotomy, biliary stent) are better served with TARE since risk of infectious complications is about half that with TAE/TACE despite broad-spectrum antibiotic coverage.

As opposed to TAE/TACE, retreating a lobe with ${ }^{90} \mathrm{Y}$ microspheres should be done with extreme caution after reviewing previously received dose due to increased risk of hepatotoxicity.

\section{Conclusion}

Decisions on the type of liver-directed embolotherapy have been traditionally been guided by institutional preference. After initial data were reported on the efficacy and shortterm safety of TARE in NETLMs, longer-term follow-up shed light on potential hepatotoxicity. While additional prospective comparative studies are needed to define the optimal embolotherapy, TARE remains a valid treatment option, but should be given with caution. Due to the heterogeneity of NETs, a more personalized approach to the type of embolotherapy is needed, especially when using TARE. The advent of new TARE dosimetry software will potentially allow for more accurate activity prescription to deliver the optimal treatment dose into the tumor while preserving the normal liver parenchyma. Finally, more prospective data are required to improve patient selection and sequencing of TARE with other therapies.

\section{Conflict of Interest}

None declared.

\section{References}

1 Dasari A, Shen C, Halperin D, et al. Trends in the incidence, prevalence, and survival outcomes in patients with neuroendocrine tumors in the United States. JAMA Oncol 2017;3(10):1335-1342

2 Riihimäki M, Hemminki A, Sundquist K, et al. The epidemiology of metastases in neuroendocrine tumors. Int J Cancer 2016;139(12): 2679-2686

3 Modlin IM, Lye KD, Kidd M. A 5-decade analysis of 13,715 carcinoid tumors. Cancer 2003;97(04):934-959

4 Oberg K, Eriksson B. Endocrine tumours of the pancreas. Best Pract Res Clin Gastroenterol 2005;19(05):753-781
5 Janson ET, Holmberg L, Stridsberg M, et al. Carcinoid tumors: analysis of prognostic factors and survival in 301 patients from a referral center. Ann Oncol 1997;8(07):685-690

6 Yao JC, Eisner MP, Leary C, et al. Population-based study of islet cell carcinoma. Ann Surg Oncol 2007;14(12):3492-3500

7 Halperin DM, Shen C, Dasari A, et al. Frequency of carcinoid syndrome at neuroendocrine tumour diagnosis: a populationbased study. Lancet Oncol 2017;18(04):525-534

8 Mota JM, Sousa LG, Riechelmann RP. Complications from carcinoid syndrome: review of the current evidence. Ecancermedicalscience 2016;10:662

9 Tomassetti P, Campana D, Piscitelli L, et al. Endocrine pancreatic tumors: factors correlated with survival. Ann Oncol 2005;16(11): 1806-1810

10 Pavel M, O’Toole D, Costa F, et al;Vienna Consensus Conference participants. ENETS Consensus guidelines update for the management of distant metastatic disease of intestinal, pancreatic, bronchial neuroendocrine neoplasms (NEN) and NEN of unknown primary site. Neuroendocrinology 2016;103(02):172-185

11 Strosberg JR, Halfdanarson TR, Bellizzi AM, et al. The North American Neuroendocrine Tumor Society Consensus Guidelines for surveillance and medical management of midgut neuroendocrine tumors. Pancreas 2017;46(06):707-714

12 Gaba RC. Chemoembolization practice patterns and technical methods among interventional radiologists: results of an online survey. AJR Am J Roentgenol 2012;198(03):692-699

13 Shah MH, Goldner WS, Halfdanarson TR, et al. NCCN Guidelines insights: neuroendocrine and adrenal tumors, version 2.2018. J Natl Compr Canc Netw 2018;16(06):693-702

14 Breedis C, Young G. The blood supply of neoplasms in the liver. Am J Pathol 1954;30(05):969-977

15 Campbell AM, Bailey IH, Burton MA. Tumour dosimetry in human liver following hepatic yttrium-90 microsphere therapy. Phys Med Biol 2001;46(02):487-498

16 Kennedy AS, Nutting C, Coldwell D, et al. Pathologic response and microdosimetry of (90)Y microspheres in man: review of four explanted whole livers. Int J Radiat Oncol Biol Phys 2004;60(05): 1552-1563

17 Gulpinar B, Peker E, Kul M, et al. Liver metastases of neuroendocrine tumors: is it possible to diagnose different histologic subtypes depending on multiphasic CT features? Abdom Radiol (NY) 2019;44(06):2147-2155

18 Neperud J, Mahvash A, Garg N, et al. Can imaging patterns of neuroendocrine hepatic metastases predict response yttrium-90 radioembolotherapy? World J Radiol 2013;5(06):241-247

19 Sato KT, Omary RA, Takehana C, et al. The role of tumor vascularity in predicting survival after yttrium-90 radioembolization for liver metastases. J Vasc Interv Radiol 2009;20(12): 1564-1569

20 Boas FE, Brody LA, Erinjeri JP, et al. Quantitative measurements of enhancement on preprocedure triphasic $\mathrm{CT}$ can predict response of colorectal liver metastases to radioembolization. AJR Am J Roentgenol 2016;207(03):671-675

21 Morsbach F, Sah BR, Spring L, et al. Perfusion CT best predicts outcome after radioembolization of liver metastases: a comparison of radionuclide and CT imaging techniques. Eur Radiol 2014; 24(07):1455-1465

22 Sato K, Lewandowski RJ, Bui JT, et al. Treatment of unresectable primary and metastatic liver cancer with yttrium-90 microspheres (TheraSphere): assessment of hepatic arterial embolization. Cardiovasc Intervent Radiol 2006;29(04):522-529

23 Vesselle G, Petit I, Boucebci S, et al. Radioembolization with yttrium-90 microspheres work up: practical approach and literature review. Diagn Interv Imaging 2015;96(06):547-562

24 Salem R, Lewandowski RJ, Sato KT, et al. Technical aspects of radioembolization with $90 \mathrm{Y}$ microspheres. Tech Vasc Interv Radiol 2007;10(01):12-29 
25 Morgan B, Kennedy AS, Lewington V, et al. Intra-arterial brachytherapy of hepatic malignancies: watch the flow. Nat Rev Clin Oncol 2011;8(02):115-120

26 Kennedy AS, Kleinstreuer C, Basciano CA, et al. Computer modeling of yttrium-90-microsphere transport in the hepatic arterial tree to improve clinical outcomes. Int J Radiat Oncol Biol Phys 2010;76(02):631-637

27 Ho S, Lau WY, Leung TW, et al. Tumour-to-normal uptake ratio of $90 \mathrm{Y}$ microspheres in hepatic cancer assessed with $99 \mathrm{Tcm}$ macroaggregated albumin. Br J Radiol 1997;70(836):823-828

28 Horsman MR, Overgaard J. The impact of hypoxia and its modification of the outcome of radiotherapy. J Radiat Res (Tokyo) 2016; 57(Suppl 1):i90-i98

29 Folkman J, Camphausen K. Cancer. What does radiotherapy do to endothelial cells? Science 2001;293(5528):227-228

30 Lewandowski RJ, Sato KT, Atassi B, et al. Radioembolization with 90Y microspheres: angiographic and technical considerations. Cardiovasc Intervent Radiol 2007;30(04):571-592

31 Liu DM, Salem R, Bui JT, et al. Angiographic considerations in patients undergoing liver-directed therapy. J Vasc Interv Radiol 2005;16(07):911-935

32 Bastiaannet R, Kappadath SC, Kunnen B, et al. The physics of radioembolization. EJNMMI Phys 2018;5(01):22

33 Wasan HS, Gibbs P, Sharma NK, et al;FOXFIRE Trial Investigators SIRFLOX Trial Investigators FOXFIRE-Global Trial Investigators. First-line selective internal radiotherapy plus chemotherapy versus chemotherapy alone in patients with liver metastases from colorectal cancer (FOXFIRE, SIRFLOX, and FOXFIRE-Global): a combined analysis of three multicentre, randomised, phase 3 trials. Lancet Oncol 2017;18(09):1159-1171

34 Abbott AM, Kim R, Hoffe SE, et al. Outcomes of TheraSphere radioembolization for colorectal metastases. Clin Colorectal Cancer 2015;14(03):146-153

35 Salem R, Gabr A, Riaz A, et al. Institutional decision to adopt Y90 as primary treatment for hepatocellular carcinoma informed by a 1,000 patient 15-year experience. Hepatology 2018;68(04):1429-1440

36 Chiesa C, Mira M, Maccauro M, et al. Radioembolization of hepatocarcinoma with (90)Y glass microspheres: development of an individualized treatment planning strategy based on dosimetry and radiobiology. Eur J Nucl Med Mol Imaging 2015;42 (11):1718-1738

37 Mikell JK, Mahvash A, Siman W, et al. Comparing voxel-based absorbed dosimetry methods in tumors, liver, lung, and at the liver-lung interface for $(90) Y$ microsphere selective internal radiation therapy. EJNMMI Phys 2015;2(01):16

38 Wondergem M, Smits ML, Elschot M, et al. 99mTc-macroaggregated albumin poorly predicts the intrahepatic distribution of $90 Y$ resin microspheres in hepatic radioembolization. J Nucl Med 2013;54(08):1294-1301

39 Elschot M, Nijsen JF, Lam MG, et al. $\left({ }^{99} \mathrm{~m}\right) \mathrm{Tc}-\mathrm{MAA}$ overestimates the absorbed dose to the lungs in radioembolization: a quantitative evaluation in patients treated with ${ }^{166} \mathrm{Ho}$-microspheres. Eur J Nucl Med Mol Imaging 2014;41(10):1965-1975

40 Yu N, Srinivas SM, Difilippo FP, et al. Lung dose calculation with SPECT/CT for ${ }^{90}$ yttrium radioembolization of liver cancer. Int J Radiat Oncol Biol Phys 2013;85(03):834-839

41 Ilhan H, Goritschan A, Paprottka P, et al. Predictive value of 99mTcMAA SPECT for 90Y-labeled resin microsphere distribution in radioembolization of primary and secondary hepatic tumors. J Nucl Med 2015;56(11):1654-1660

42 Ulrich G, Dudeck O, Furth C, et al. Predictive value of intratumoral $99 \mathrm{mTc}$-macroaggregated albumin uptake in patients with colorectal liver metastases scheduled for radioembolization with $90 \mathrm{Y}-$ microspheres. J Nucl Med 2013;54(04):516-522

43 Garin E, Lenoir L, Edeline J, et al. Boosted selective internal radiation therapy with 90Y-loaded glass microspheres (B-SIRT) for hepatocellular carcinoma patients: a new personalized prom- ising concept. Eur J Nucl Med Mol Imaging 2013;40(07): 1057-1068

44 Garin E, Rolland Y, Edeline J, et al. Personalized dosimetry with intensification using 90Y-loaded glass microsphere radioembolization induces prolonged overall survival in hepatocellular carcinoma patients with portal vein thrombosis. J Nucl Med 2015;56(03):339-346

45 Gnesin S, Canetti L, Adib S, et al. Partition model based 99mTcMAA SPECT/CT predictive dosimetry compared to 90Y TOF PET/ CT post-treatment dosimetry in radioembolisation of hepatocellular carcinoma: a quantitative agreement comparison. J Nucl Med 2016;57(11):1672-1678

46 Chansanti O, Jahangiri Y, Matsui Y, et al. Tumor dose response in yttrium-90 resin microsphere embolization for neuroendocrine liver metastases: a tumor-specific analysis with dose estimation using SPECT-CT. J Vasc Interv Radiol 2017;28(11):1528-1535

47 Barbier CE, Garske-Román U, Sandström M, et al. Selective internal radiation therapy in patients with progressive neuroendocrine liver metastases. Eur J Nucl Med Mol Imaging 2016;43(08): 1425-1431

48 Braat AJAT, Kappadath SC, Ahmadzadehfar H, et al. Radioembolization with ${ }^{90} \mathrm{Y}$ resin microspheres of neuroendocrine liver metastases: international multicenter study on efficacy and toxicity. Cardiovasc Intervent Radiol 2019;42(03):413-425

49 Kennedy A, Bester L, Salem R, et al.PNET-Liver-Metastases Consensus Conference. Role of hepatic intra-arterial therapies in metastatic neuroendocrine tumours (NET): guidelines from the NET-Liver-Metastases Consensus Conference. HPB (Oxford) 2015; 17(01):29-37

50 Elf AK, Andersson M, Henrikson O, et al. Radioembolization versus bland embolization for hepatic metastases from small intestinal neuroendocrine tumors: short-term results of a randomized clinical trial. World J Surg 2018;42(02):506-513

51 Devcic Z, Rosenberg J, Braat AJ, et al. The efficacy of hepatic 90Y resin radioembolization for metastatic neuroendocrine tumors: a meta-analysis. J Nucl Med 2014;55(09):1404-1410

52 Frilling A, Clift AK, Braat AJAT, et al. Radioembolisation with 90Y microspheres for neuroendocrine liver metastases: an institutional case series, systematic review and meta-analysis. HPB (Oxford) 2019;21(07):773-783

53 Jia Z, Wang W. Yttrium-90 radioembolization for unresectable metastatic neuroendocrine liver tumor: a systematic review. Eur J Radiol 2018;100:23-29

54 Chen JX, Rose S, White SB, et al. Embolotherapy for neuroendocrine tumor liver metastases: prognostic factors for hepatic progression-free survival and overall survival. Cardiovasc Intervent Radiol 2017;40(01):69-80

55 Tsang ES, Loree JM, Davies JM, et al. Efficacy and prognostic factors for Y-90 radioembolization (Y-90) in metastatic neuroendocrine tumors with liver metastases. Can J Gastroenterol Hepatol 2020; 2020:5104082

56 Zuckerman DA, Kennard RF, et al. Outcomes and toxicity following yttrium-90 radioembolization for hepatic metastases from neuroendocrine tumors-a single-institution experience. J Gastrointest Oncol 2019;10(01):118-127

57 Kennedy AS, Dezarn WA, McNeillie P, et al. Radioembolization for unresectable neuroendocrine hepatic metastases using resin 90Ymicrospheres: early results in 148 patients. Am J Clin Oncol 2008; 31(03):271-279

58 Frilling A, Modlin IM, Kidd M, et al.Working Group on Neuroendocrine Liver Metastases. Recommendations for management of patients with neuroendocrine liver metastases. Lancet Oncol 2014;15(01):e8-e21

59 Vogl TJ, Naguib NN, Zangos S, et al. Liver metastases of neuroendocrine carcinomas: interventional treatment via transarterial embolization, chemoembolization and thermal ablation. Eur J Radiol 2009;72(03):517-528 
60 Engelman ES, Leon-Ferre R, Naraev BG, et al. Comparison of transarterial liver-directed therapies for low-grade metastatic neuroendocrine tumors in a single institution. Pancreas 2014;43(02):219-225

61 Rhee TK, Lewandowski RJ, Liu DM, et al. 90Y radioembolization for metastatic neuroendocrine liver tumors: preliminary results from a multi-institutional experience. Ann Surg 2008;247(06):1029-1035

62 Memon K, Lewandowski RJ, Mulcahy MF, et al. Radioembolization for neuroendocrine liver metastases: safety, imaging, and longterm outcomes. Int J Radiat Oncol Biol Phys 2012;83(03):887-894

63 Whitney R, Vàlek V, Fages JF, et al. Transarterial chemoembolization and selective internal radiation for the treatment of patients with metastatic neuroendocrine tumors: a comparison of efficacy and cost. Oncologist 2011;16(05):594-601

64 Egger ME, Armstrong E, Martin RC II, et al. Transarterial chemoembolization vs radioembolization for neuroendocrine liver metastases: a multi-institutional analysis. J Am Coll Surg 2020;230 (04):363-370

65 Cao CQ, Yan TD, Bester L, et al. Radioembolization with yttrium microspheres for neuroendocrine tumour liver metastases. Br J Surg 2010;97(04):537-543

66 Saxena A, Chua TC, Bester L, et al. Factors predicting response and survival after yttrium-90 radioembolization of unresectable neuroendocrine tumor liver metastases: a critical appraisal of 48 cases. Ann Surg 2010;251(05):910-916

67 Bester L, Meteling B, Pocock N, et al. Radioembolisation with yttrium-90 microspheres: an effective treatment modality for unresectable liver metastases. J Med Imaging Radiat Oncol 2013; 57(01):72-80

68 Sangro B, Martínez-Urbistondo D, Bester L, et al. Prevention and treatment of complications of selective internal radiation therapy: expert guidance and systematic review. Hepatology 2017;66 (03):969-982

69 Devulapalli KK, Fidelman N, Soulen MC, et al. ${ }^{90} \mathrm{Y}$ radioembolization for hepatic malignancy in patients with previous biliary intervention: multicenter analysis of hepatobiliary infections. Radiology 2018;288(03):774-781

70 Su YK, Mackey RV, Riaz A, et al. Long-term hepatotoxicity of yttrium90 radioembolization as treatment of metastatic neuroendocrine tumor to the liver. J Vasc Interv Radiol 2017;28(11):1520-1526

71 Currie BM, Hoteit MA, Ben-Josef E, et al. Radioembolizationinduced chronic hepatotoxicity: a single-center cohort analysis. J Vasc Interv Radiol 2019;30(12):1915-1923

72 Tomozawa Y, Jahangiri Y, Pathak P, et al. Long-term toxicity after transarterial radioembolization with yttrium-90 using resin microspheres for neuroendocrine tumor liver metastases. J Vasc Interv Radiol 2018;29(06):858-865

73 Sangro B, Gil-Alzugaray B, Rodriguez J, et al. Liver disease induced by radioembolization of liver tumors: description and possible risk factors. Cancer 2008;112(07):1538-1546
74 Currie BM, Nadolski G, Mondschein J, et al. Chronic hepatotoxicity in patients with metastatic neuroendocrine tumor: transarterial chemoembolization versus transarterial radioembolization. J Vasc Interv Radiol 2020;31(10):1627-1635

75 Kim HS, Shaib WL, Zhang C, et al. Phase 1b study of pasireotide, everolimus, and selective internal radioembolization therapy for unresectable neuroendocrine tumors with hepatic metastases. Cancer 2018;124(09):1992-2000

76 Soulen MC, van Houten D, Teitelbaum UR, et al. Safety and feasibility of integrating yttrium-90 radioembolization with capecitabine-temozolomide for grade 2 liver-dominant metastatic neuroendocrine tumors. Pancreas 2018;47(08):980-984

77 King J, Quinn R, Glenn DM, et al. Radioembolization with selective internal radiation microspheres for neuroendocrine liver metastases. Cancer 2008;113(05):921-929

78 Food and Drug Administration. FDA approves lutetium Lu 177 dotatate for treatment of GEP-NETS. Accessed January 26, 2018 at: https://www.accessdata.fda.gov/drugsatfda_docs/label/2018/ 208700s000lbl.pdf

79 Strosberg J, El-Haddad G, Wolin E, et al;NETTER-1 Trial Investigators. Phase 3 trial of ${ }^{177} \mathrm{Lu}$-dotatate for midgut neuroendocrine tumors. N Engl J Med 2017;376(02):125-135

80 Brabander T, van der Zwan WA, Teunissen JJM, et al. Long-term efficacy, survival, and safety of $\left[{ }^{177} \mathrm{Lu}^{-D O T A}{ }^{0}, \mathrm{Tyr}^{3}\right]$ octreotate in patients with gastroenteropancreatic and bronchial neuroendocrine tumors. Clin Cancer Res 2017;23(16):4617-4624

81 Hamiditabar M, Ali M, Bolek L, et al. Safety and effectiveness of 177Lu-DOTATATE peptide receptor radionuclide therapy after regional hepatic embolization in patients with somatostatinexpressing neuroendocrine tumors. Clin Nucl Med 2017;42(11): 822-828

82 Riff BP, Yang YX, Soulen MC, et al. Peptide receptor radionuclide therapy-induced hepatotoxicity in patients with metastatic neuroendocrine tumors. Clin Nucl Med 2015;40(11):845-850

83 Braat AJAT, Ahmadzadehfar H, Kappadath SC, et al. Radioembolization with ${ }^{90} \mathrm{Y}$ resin microspheres of neuroendocrine liver metastases after initial peptide receptor radionuclide therapy. Cardiovasc Intervent Radiol 2020;43(02):246-253

84 Aras M, Erdil TY, Dane F, et al. Comparison of WHO, RECIST 1.1, EORTC, and PERCIST criteria in the evaluation of treatment response in malignant solid tumors. Nucl Med Commun 2016; 37(01):9-15

85 Therasse P, Arbuck SG, Eisenhauer EA, et al. New guidelines to evaluate the response to treatment in solid tumors. European Organization for Research and Treatment of Cancer, National Cancer Institute of the United States, National Cancer Institute of Canada. J Natl Cancer Inst 2000;92(03):205-216

86 Lencioni R, Llovet JM. Modified RECIST (mRECIST) assessment for hepatocellular carcinoma. Semin Liver Dis 2010;30(01):52-60 